\title{
Evolução da população rural ocupada nas Grandes Regiões do Brasil entre 2001 e 2009
}

\author{
Rural population occupied development in the Regions of Brazil from \\ 2001 to 2009
}

\section{Evolution de la population rurale dans les régions du Brésil entre 2001 et 2009 \\ Evolución de La poblacion rural ocupada en las Regiones de Brasil entre 2001 y 2009}

\author{
Tiago Santos Telles* \\ Gustavo Vaz da Costa* \\ Matheus Demambre Bacchi* \\ Antonio Carlos Laurenti*
}

Recebido em 14/07/2016; revisado e aprovado em 31/10/2016; aceito em 31/10/2016

DOI: http:/ / dx.doi.org/10.20435/1984-042X-2017-v.18-n.1(02)

\begin{abstract}
Resumo: O presente estudo teve por objetivo analisar a evolução da população economicamente ativa (PEA) ocupada, por situação de domicílio, sobretudo rural, em setor de atividade, agrícola e não agrícola, nas Grandes Regiões do Brasil, entre 2001 e 2009. Verificou-se um declínio da PEA rural ocupada em atividades agrícolas nas Grandes Regiões consideradas no estudo. Todavia esta redução foi parcialmente compensada pela expansão da PEA rural ocupada em atividades não agrícolas, levando ao aumento da PEA rural.
\end{abstract}

Palavras-chave: PEA; atividades agrícolas; atividades não agrícolas.

Abstract: The aim of this study was to analyze the occupied economically active population (EAP) developments, according to residence, mainly in rural, and, activity sector (agriculture and off-agriculture activities), in the Brazilian Regions, from 2001 to 2009. It was verified a decline of the rural EAP with agricultural occupation in the Brazilian Regions. However, this reduction, was partially compensated by rural EAP with off-agricultural occupation growth leading to increase the rural EAP.

Key words: EAP; agriculture activity; off-agriculture activity.

Résumé: Cette étude visait à analyser l'évolution de la population économiquement active (PEA) occupé par la situation des ménages, en particulier en milieu rural, et le secteur des entreprises, agricoles et non agricoles, les régions du Brésil entre 2001 et 2009. Il a été trouvé une baisse de PEA en milieu rural engagés dans des activités agricoles dans les régions du Brésil. Cependant, cette réduction a été en partie compensée par l'expansion de PEA en milieu rural engagés dans des activités non agricoles, conduisant à une augmentation PEA en milieu rural.

Mots-clés: PEA; activités agricoles; activités non agricoles.

Resumen: Este estudio tuvo por finalidad analizar la evolución de la población economicamente activa (PEA) ocupada, por situación de hogar, sobretodo rural, y por sector de actividad, agrícola y no agrícola, según las Regiones de Brasil, entre 2001 y 2009. Se verificó una disminución en la PEA ocupada en actividades agrícolas en todas las Regiones de Brasil. Sin embargo esta reducción fue en parte compensada pos la expansión de la PEA rural ocupada en actividades no agrícolas, llevando al aumento de la PEA rural.

Palabras clave: PEA; actividades agrícolas; actividades no agrícolas.

\section{INTRODUÇÃO}

A economia da área rural brasileira não se restringe às atividades relacionadas à agropecuária. Nas últimas décadas, o meio rural ganhou novas funções - agrícolas e não agrícolas - e oportunidades de trabalho e renda para os indivíduos que ali residem. Desde a década de 1980, há evidências de que transformações

\footnotetext{
* Instituto Agronômico do Paraná (IAPAR), Londrina, Paraná, Brasil.
} 
significativas vinham ocorrendo no meio rural brasileiro, em função da modernização da agricultura e do desenvolvimento dos centros urbanos, de forma que a agropecuária moderna e a agricultura de subsistência passaram a dividir espaço com um conjunto de atividades ligadas ao comércio, serviços e indústria, reduzindo cada vez mais, as diferenças entre o rural e o urbano. Essas tendências foram constatadas, para o Brasil, seminalmente, por importantes pensadores do século XX, como Milton Santos (SANTOS, 2005) e Gilberto Freyre (FROEHLICH, 2000).

Entre as décadas de 1960 e 1980, por um lado, com a modernização da agricultura, uma quantidade menor de pessoas passou a ser necessária para a execução das atividades agrícolas, tornando corriqueiro o jargão de que a máquina substitui o homem. Por outro lado, as pessoas tinham nos centros urbanos, em plena expansão, expectativas por uma vida de melhor qualidade, com acesso a bens e serviços que não estavam disponíveis no meio rural da época. Ainda na década de 1980, observava-se que a população remanescente do meio rural passou a realizar atividades não exclusivamente agrícolas, como já ocorria nos países considerados desenvolvidos (GRAZIANO DA SILVA, 1997).

A partir de 1990, a população economicamente ativa (PEA) rural passou a exibir um novo perfil ocupacional, mostrando alterações no sentido da expansão da ocupação em atividades não agrícolas, além de um crescimento da parcela populacional, de 10 anos ou mais, residente no meio rural, com ocupação no meio urbano. Essa constatação foi verificada por meio do Projeto Rurbano, denominado "Caracterização do Novo Rural Brasileiro", que teve início em 1997, com o objetivo de investigar a dinâmica do emprego agrícola nas áreas rurais do território nacional. A partir desse estudo, pode-se verificar a interrupção da redução do tamanho e a crescente diversificação ocupacional da população rural (GRAZIANO DA SILVA, 2001; GRAZIANO DA SILVA; DEL GROSSI, 2001; LAURENTI, 2014).

Essa tendência, em particular, a expansão da população ocupada em atividades não agrícolas, possibilitou uma nova e mais abrangente abordagem acerca do meio rural brasileiro, cujo perfil vem sendo realçado pela contínua redução da população rural ocupada na agricultura mercantil. Em síntese, havia três situações: primeiro, que existiam pessoas residentes do meio rural com ocupação em atividades agrícolas; segundo, que havia pessoas residentes no meio rural com ocupação em atividades não agrícolas; e terceiro, que havia residentes do meio urbano com ocupação em atividades agrícolas.

Dessa forma, a evolução dos estudos permitiu o entendimento do decréscimo da PEA rural ocupada em atividades agrícolas e da elevação da PEA rural ocupada em atividades não agrícolas (LAURENTI; PELLINI; TELLES, 2015). Pode-se afirmar que a situação observada está associada ao processo crescente de uma população rural ocupada em atividades agrícolas e não agrícolas simultaneamente.

Nos anos 2000, outros trabalhos analisaram dinâmicas populacionais referentes às pessoas ocupadas no meio rural. Del Grossi e Graziano da Silva (2006), Ferreira et al. (2006), Balsadi e Gomes (2007) e Laurenti, Pellini e Telles (2015), fizeram uma análise acerca do território nacional. Balsadi (2005) e Balsadi e Borin (2006), para o estado de São Paulo, Bazotti et al. (2009) e Laurenti (2013), para o Paraná, Balsadi (2008), para o Centro-Oeste e Alves e Paulo (2012), para o Ceará. Em sua maioria, a partir dos dados da Pesquisa Nacional por Amostra de Domicílios (PNAD), do Instituto Brasileiro de Geografia e Estatística (IBGE), os estudos levam ao reconhecimento da continuidade do declínio da PEA rural ocupada em atividades agrícolas e o crescimento das atividades não agrícolas. 
Mesmo com a ampla literatura acerca dessa temática, há uma escassez de pesquisas que enfatizem uma comparação dessas tendências populacionais entre as diferentes regiões do Brasil. A fim de explicar como se deu o decréscimo da PEA rural ocupada, nas Grandes Regiões do país, e verificar se as tendências observadas são as mesmas daquelas constatadas para o país, bem como as principais diferenças entre as Grandes Regiões, é justificável o esforço de apurar, de modo mais detalhado, a continuidade da redução absoluta da PEA ocupada em atividades agrícolas e sua genérica associação com o processo de modernização da agricultura. Tal descrição poderá subsidiar, de modo mais seguro, ou com maior abrangência, o delineamento de ações públicas dirigidas à melhoria e ao desenvolvimento do meio rural.

Nesse contexto, a presente análise está calcada na hipótese de que a intensidade do decréscimo da PEA rural ocupada se deu de forma desigual entre as Grandes Regiões, tanto com relação à situação de domicílio, quanto ao setor de atividade, fruto, da desigual incidência do desenvolvimento da agricultura no território brasileiro.

Com isso, o presente estudo teve por objetivo analisar a evolução da PEA ocupada, por situação de domicílio, sobretudo no meio rural, e setor de atividade, nas Grandes Regiões do Brasil, entre os anos de 2001 e 2009.

O trabalho está dividido em mais três seções além desta introdução. A segunda apresenta a metodologia utilizada para aferir as tendências de variação dos grupos populacionais considerados nessa pesquisa. Na terceira seção, são apresentados os resultados e discussão, que, de modo geral, tratam do decréscimo da PEA rural ocupada em atividades agrícolas. Por fim, a quarta e última seção exibe as considerações finais.

\section{MATERIAL E MÉTODOS}

As dinâmicas da PEA ocupada nas Grandes Regiões do Brasil foram analisadas a partir da base de microdados da PNAD, do IBGE, dos anos de 2001 a 2009. Para processamento e análise dos dados, foi utilizado o software IBM SPSS ${ }^{\circledR}$ 21.0.

A averiguação proposta se conduziu para as Grandes Regiões do Brasil, exclusive a Grande Região Norte, que, para anos anteriores a 2004, não apresentou informações acerca das áreas rurais. Além disso, nessa caracterização foi utilizada a delimitação da área rural e a contagem da população considerada pelo IBGE, para as finalidades da PNAD e do Censo Demográfico, que resultam da delimitação dos perímetros urbanos pelos legisladores municipais, mantida durante todo o período intercensitário. Ademais, na contagem da população rural, não se contabiliza o habitante de sede distrital ou de vila, que é legalmente considerado como morador urbano, sendo, portanto, integrante da população urbana. A não alteração dos limites dos referidos perímetros no período intercensitário, bem como a utilização dos microdados reponderados, faculta e abaliza a comparabilidade interanual das PNAD.

Em cada Grande Região foram considerados nas análises dois níveis hierárquicos: situação de domicílio e setor de atividade. Com relação à situação de domicílio, a PEA ocupada foi dividida em rural e urbana. Já os setores de atividade foram subdivididos em agrícola e não agrícola, conforme as PNAD.

A caracterização das tendências de variação dos subgrupos populacionais presentes na PEA domiciliada nos meios rural e urbano, ocupada em atividades agrícola e não agrícola, foi elaborada tendo como base a taxa média anual de variação, correspondente ao coeficiente da equação do tipo log-linear pelo método de regressão de mínimos quadrados ordinários (MQO), o qual correlaciona 
a estimativa do tamanho da população ao correspondente ano de observação, conforme Equação 1 (HOFFMANN, 2006, p. 41). Essa taxa de variação foi expressa em percentual, com a aceitabilidade das hipóteses aferidas pela aplicação do teste $t$ de Student, considerando níveis de 5\%, $10 \%$ e $20 \%$ de significância.

$$
Y_{i}=\alpha+\beta X_{i}+\mu_{i} \quad i=1,2, \ldots, n .
$$

Sendo: $a$ o intercepto; $\beta$ o coeficiente angular da reta; $X$ a variável explanatória referente ao ano correspondente à $i$-ésima observação; $Y$ a variável dependente referente aos subgrupos populacionais presentes na PEA domiciliada nos meios rural e urbano, ocupada em atividades agrícola e não agrícola no $i$-ésimo ano; $\mu$ o erro aleatório; e $i$ o número de anos.

\section{RESULTADOS E DISCUSSÃO}

Os resultados referentes à evolução da PEA ocupada nas Grandes Regiões do Brasil, por situação de domicílio e setor de atividade principal, no período de 2001 a 2009, são apresentados na Tabela 1. Com relação à PEA total ocupada em atividades agrícolas, em termos absolutos, houve um decréscimo nas Grandes Regiões do Brasil, com exceção da Centro-Oeste, na qual houve um aumento de $0,8 \%$ a.a. $\mathrm{O}$ decréscimo foi mais intenso na região Sul (-2,6\%a.a.), seguida pelas regiões Nordeste $(-0,9 \%$ a.a. $)$ e Sudeste $(-0,4 \%$ a.a. $)$.

Tabela 1 - População economicamente ativa, ocupada nas Grandes Regiões do Brasil, por setor de atividade principal, entre 2001 e 2009

\begin{tabular}{|c|c|c|c|c|c|c|c|c|c|c|c|}
\hline \multirow{2}{*}{$\mathrm{GR}^{1}$} & \multirow{2}{*}{$\begin{array}{l}\text { Setor de } \\
\text { atividade }\end{array}$} & 001 & 2002 & 2003 & 2004 & 2005 & 2006 & 2007 & 2008 & 2009 & \multirow{2}{*}{2} \\
\hline & & \multicolumn{9}{|c|}{ Milhares de pessoas } & \\
\hline \multirow{3}{*}{ Nordeste } & Agrícola & 7.535 & 7.911 & 8.185 & 8.162 & 8.418 & 7.964 & 7.715 & 7.502 & 7.132 & $-0,9^{*}$ \\
\hline & Não agrícola & 13.225 & 13.696 & 13.793 & 14.358 & 14.887 & 15.544 & 15.972 & 16.751 & 16.904 & $3,3^{* * *}$ \\
\hline & Total & 20.759 & 21.607 & 21.978 & 22.520 & 23.305 & 23.507 & 23.687 & 24.253 & 24.036 & $1,9 * * *$ \\
\hline \multirow{3}{*}{$\begin{array}{c}\text { Centro- } \\
\text { Oeste }\end{array}$} & Agr & 993 & & & 1.077 & 1.120 & 1.066 & 1.107 & & 1.079 & $08 * *$ \\
\hline & Não ag & 4.631 & 4.815 & 4.833 & 5.156 & 5.233 & 5.434 & 5.678 & 5.953 & 6.062 & $3,5^{* * *}$ \\
\hline & Total & 5.624 & 5.846 & 5.878 & 6.232 & 6.352 & 6.500 & 6.784 & 7.004 & 7.141 & $3,1^{* * *}$ \\
\hline \multirow{3}{*}{ Sudeste } & Agrícola & 3.548 & 3.601 & 3.571 & 3.518 & 3.658 & 3.672 & 3.405 & 3.494 & 3.460 & $-0,4^{*}$ \\
\hline & Não agrícola & 29.321 & 30.349 & 30.686 & 31.676 & 32.826 & 34.028 & 34.773 & 36.017 & 36.257 & $2,8^{* * *}$ \\
\hline & Total & 32.869 & 33.950 & 34.256 & 35.194 & 36.484 & 37.700 & 38.178 & 39.512 & 39.717 & $2,5^{* * *}$ \\
\hline \multirow{3}{*}{ Sul } & Agrícola & 3.079 & 3.247 & 3.241 & 3.161 & 3.111 & 3.041 & 2.839 & 2.682 & 2.573 & $-2,6^{* * *}$ \\
\hline & Não agrícola & 9.850 & 10.108 & 10.300 & 10.800 & 10.918 & 11.227 & 11.631 & 11.860 & 12.087 & $2,7^{* * *}$ \\
\hline & Total & 12.929 & 13.355 & 13.541 & 13.961 & 14.030 & 14.268 & 14.470 & 14.541 & 14.661 & $1,5^{\star * *}$ \\
\hline
\end{tabular}

Fonte: Elaborado pelos autores com base nos microdados da Pesquisa Nacional de Amostra por Domicílios (PNAD), do Instituto Brasileiro de Geografia e Estatística (IBGE).

Notas: ${ }^{1}$ Taxa média anual de crescimento, estimada pelo coeficiente da regressão log-linear em função do tempo. Sendo que ***, ${ }^{* *},{ }^{*}$ indicam, respectivamente, o nível de significância de $5 \%, 10 \%$ ou, 20\%, pelo teste $\mathrm{t}$ de Student, e NS, não significativo.

Na região Nordeste, embora a PEA total ocupada em atividades agrícolas representem em média $34 \%$ da PEA total ocupada, entre 2001 e 2009, houve um decréscimo na participação relativa desta. Além disso, a despeito do declínio da PEA total ocupada em atividades agrícolas, em números absolutos, a região Nordeste se destaca entre as demais por possuir o maior contingente nesse subgrupo populacional. Inclusive, entre 2002 e 2009, a PEA total ocupada em atividades agrícolas no Nordeste foi superior à soma desta, em todas as outras Grandes Regiões. Isso 
evidencia, mesmo em um contexto de queda, a importância, nos anos 2000, das atividades agrícolas para a população nordestina.

Na região Centro-Oeste, em termos absolutos, a PEA total ocupada em atividades agrícolas apresentou, em média, 1,1 milhão de pessoas, com uma participação relativa em média de $17 \%$ da PEA total ocupada. Vale destacar que, na região Centro-Oeste, durante os anos 2000, houve um aumento das áreas destinadas às atividades agropecuárias (FREITAS; MENDONÇA; LOPES, 2011; SAUER; LEITE, 2012). Assim, mesmo em se tratando de uma região pautada em uma agricultura extremamente moderna, empresarial, baseada no cultivo de grãos, com predomínio de unidades produtivas com grandes áreas em função da incorporação de novas áreas, houve, provavelmente, um aumento no número de postos de ocupação.

Em relação à região Sudeste, a média da PEA total ocupada em atividades agrícolas foi de 3,5 milhões de pessoas em termos absolutos. Já em termos relativos, esta possuiu uma participação média de $10 \%$ em relação à sua PEA total ocupada. Assim, embora em termos absolutos seja a segunda região do país com o maior contingente populacional nesse subgrupo, em termos relativos é onde a PEA total ocupada em atividades agrícolas apresenta menor importância.

Já na região Sul, a PEA total ocupada em atividades agrícolas, em média, foi de 3 milhões de pessoas, em valores absolutos. Já a participação relativa desta foi de $22 \%$ da PEA total ocupada em média. Ou seja, trata-se de uma Grande Região do país na qual os postos de ocupação nas atividades agrícolas ainda têm grande relevância na composição da PEA total ocupada.

Na Tabela 2, são apresentados os resultados acerca da PEA, domiciliada no meio rural, ocupada em atividades agrícolas e não agrícolas, nas Grandes Regiões do Brasil, entre 2001 e 2009.

Tabela 2 - População economicamente ativa ocupada, domiciliada no meio rural, nas Grandes Regiões do Brasil, por setor de atividade principal, entre 2001 e 2009

\begin{tabular}{|c|c|c|c|c|c|c|c|c|c|c|c|}
\hline \multirow{2}{*}{ Região } & \multirow{2}{*}{$\begin{array}{l}\text { Setor de } \\
\text { atividade }\end{array}$} & 2001 & 2002 & 2003 & 2004 & 2005 & 2006 & 2007 & 2008 & 2009 & \multirow{2}{*}{$i^{1}$} \\
\hline & & \multicolumn{9}{|c|}{ Milhares de pessoas } & \\
\hline \multirow{3}{*}{ Nordeste } & Agrícola & 5.771 & 6.042 & 6.123 & 6.011 & 6.219 & 5.977 & 5.813 & 5.621 & 5.330 & $-1,1^{* *}$ \\
\hline & Não agrícola & 1.440 & 1.428 & 1.392 & 1.471 & 1.681 & 1.656 & 1.796 & 1.789 & 1.852 & $3,9 * * *$ \\
\hline & Total & 7.210 & 7.470 & 7.515 & 7.482 & 7.900 & 7.633 & 7.609 & 7.409 & 7.182 & $0,0^{\mathrm{NS}}$ \\
\hline \multirow{3}{*}{$\begin{array}{c}\text { Centro- } \\
\text { Oeste }\end{array}$} & Agrícola & 651 & 655 & 682 & 729 & 768 & 718 & 725 & 690 & 670 & $0,6^{\mathrm{NS}}$ \\
\hline & Não agrícola & 227 & 221 & 245 & 257 & 288 & 316 & 274 & 286 & 309 & $4,1^{* * *}$ \\
\hline & Total & 878 & 876 & 928 & 986 & 1057 & 1034 & 999 & 977 & 979 & $1,6^{* * *}$ \\
\hline \multirow{3}{*}{ Sudeste } & Agrícola & 2.230 & 2.118 & 2.038 & 2.017 & 2.158 & 2.103 & 2.007 & 1.954 & 1.945 & $-1,3^{* *}$ \\
\hline & Não agrícola & 1.065 & 1.086 & 1.109 & 1.162 & 1.291 & 1.283 & 1.368 & 1.380 & 1.431 & $4,1^{* * *}$ \\
\hline & Total & 3.295 & 3.203 & 3.147 & 3.178 & 3.449 & 3.386 & 3.375 & 3.334 & 3.376 & $0,7^{* *}$ \\
\hline \multirow{3}{*}{ Sul } & Agrícola & 2.350 & 2.390 & 2.384 & 2.337 & 2.274 & 2.209 & 2.131 & 1.999 & 1.956 & $-2,6^{* * *}$ \\
\hline & Não agrícola & 641 & 683 & 692 & 726 & 750 & 779 & 803 & 884 & 877 & $4,1^{* * *}$ \\
\hline & Total & 2.991 & 3.073 & 3.076 & 3.063 & 3.024 & 2.988 & 2.933 & 2.883 & 2.834 & $-0,9^{* * *}$ \\
\hline
\end{tabular}

Fonte: Elaborado pelos autores com base nos microdados da Pesquisa Nacional de Amostra por Domicílios (PNAD), do Instituto Brasileiro de Geografia e Estatística (IBGE).

Notas: ${ }^{1}$ Taxa média anual de crescimento, estimada pelo coeficiente da regressão log-linear em função do tempo. Sendo que ${ }^{* * *},{ }^{* *},{ }^{*}$ indicam, respectivamente, o nível de significância de 5\%, 10\% ou, 20\%, pelo teste $\mathrm{t}$ de Student, e NS, não significativo. 
Quanto à PEA rural ocupada total, em termos absolutos, entre 2001 e 2009, o Nordeste apresentou a maior fração entre as Grandes Regiões analisadas, cerca de 7,5 milhões de pessoas. No entanto, nessa região, a taxa anual de crescimento não foi significativa. A região Sudeste, por sua vez, possuía aproximadamente 3,3 milhões de pessoas nessa categoria, com uma taxa anual de crescimento de 0,7\% a.a. Na Sul o número foi de 2,9 milhões de pessoas, em média, sendo a única Grande Região com decréscimo nesse subgrupo populacional $(-0,9 \%$ a.a.). Já o CentroOeste foi a região que teve a menor parcela da população na PEA rural ocupada total, em média, 900 mil pessoas, com uma taxa de crescimento de 1,6\% a.a., a maior entre as Grandes Regiões analisadas.

Em relação à PEA rural ocupada em atividades agrícolas, de forma similar, o Nordeste apresentou o maior valor absoluto, em média, cerca de 5,9 milhões de pessoas. Porém, nesse subgrupo populacional, houve um decréscimo de 1,1\% a.a. A região Sudeste deteve, em média, 2,1 milhões de pessoas, com decréscimo 1,3\% a.a. Já a região Sul, em que o contingente da PEA rural ocupada em atividades agrícolas foi em média, de 2,2 milhões de pessoas, houve um decréscimo mais intenso, $2,6 \%$ a.a. Na região Centro-Oeste, com média de 700 mil pessoas, não houve uma tendência significativa em relação à PEA rural ocupada em atividades agrícolas.

Nos anos 1980, as tendências da PEA rural ocupada em atividades agrícolas no Nordeste e no Centro-Oeste eram muito distintas das observadas neste estudo, ou seja, para década de 2000. Nessas Grandes Regiões, naquele período, a PEA rural ocupada em atividades agrícolas crescia significativamente, sobretudo pelo movimento de expansão das fronteiras agrícolas, mas esta realidade se alterou já nos anos 1990 (DEL GROSSI; GRAZIANO DA SILVA, 2006).

No que diz respeito à PEA rural ocupada em atividades não agrícolas, ob- serva-se que em todas as Grandes Regiões do Brasil houve um crescimento significativo. No Nordeste, com aproximadamente 1,6 milhão de pessoas e crescimento de $3,9 \%$ a.a. De forma subsequente, a região Sudeste com média de 1,2 milhão de pessoas, apresentou crescimento de $4,1 \%$ a.a. A Grande Região Sul, com média de 750 mil pessoas e taxa de crescimento de $4,1 \%$ a.a. Por fim, o Centro-Oeste obteve média de 270 mil pessoas e taxa de crescimento de $4,1 \%$ a.a.

Ao analisar a região Nordeste, verificou-se que, entre os anos de 2001 e 2009, houve uma participação relativa média de $78,5 \%$ da PEA rural ocupada em atividades agrícolas. No entanto, observou-se um crescimento da participação relativa das atividades não agrícolas e um decréscimo da participação relativa das atividades agrícolas. A região CentroOeste, no mesmo período, mostrou uma participação relativa média de $72 \%$ da PEA rural ocupada em atividades agrícolas, com crescimento da participação relativa das atividades não agrícolas e redução da participação relativa das atividades agrícolas, em padrões semelhantes aos apresentados pela região Nordeste. Na região Sul, observa-se uma participação relativa média de aproximadamente $74 \%$ da PEA rural ocupada nas atividades agrícolas. No entanto esta apresentou uma taxa de crescimento anual das atividades não agrícolas de forma mais acelerada que as outras regiões, com redução das taxas de crescimento das atividades agrícolas. A região Sudeste apresentou uma participação relativa média de $62,5 \%$ da PEA rural ocupada em atividades agrícolas. Houve crescimento das atividades não agrícolas e, entre todas as regiões, apresentou o maior decréscimo na participação das atividades agrícolas. Deve-se considerar que, entre todas as regiões analisadas, esta possui relevante participação das atividades não agrícolas.

Del Grossi e Graziano da Silva (2006), em um estudo para o Brasil, no 
período de 2001 a 2004, verificaram um aumento de 2,2\% a.a. na a PEA rural ocupada em atividades não agrícolas. Em estudo para os anos de 2001 a 2009, também Brasil, Laurenti, Pellini e Telles (2015) verificaram uma elevação de 4,1\% a.a. nesse mesmo setor de atividade no meio rural. Ou seja, todas as regiões ana- lisadas neste estudo acompanharam a mesma tendência observada para o país.

A Tabela 3 contém os resultados sobre a PEA, domiciliada no meio urbano, ocupada em atividades agrícolas e não agrícolas, nas Grandes Regiões do Brasil, entre 2001 e 2009.

Tabela 3 - População economicamente ativa ocupada, domiciliada no meio urbano, nas Grandes Regiões do Brasil, por setor de atividade principal, entre 2001 e 2009

\begin{tabular}{|c|c|c|c|c|c|c|c|c|c|c|c|}
\hline \multirow{2}{*}{ Região } & \multirow{2}{*}{$\begin{array}{l}\text { Setor de } \\
\text { atividade }\end{array}$} & 2001 & 2002 & 2003 & 2004 & 2005 & 2006 & 2007 & 2008 & 2009 & \multirow{2}{*}{$i^{1}$} \\
\hline & & \multicolumn{9}{|c|}{ Milhares de pessoas } & \\
\hline \multirow{3}{*}{ Nordeste } & Agrícola & 1.764 & 1.870 & 2.062 & 2.150 & 2.199 & 1.987 & 1.902 & 1.881 & 1.802 & $-0,2^{\mathrm{NS}}$ \\
\hline & Não agrícola & 11.785 & 12.268 & 12.401 & 12.887 & 13.206 & 13.888 & 14.175 & 14.963 & 15.052 & $3,2 * * *$ \\
\hline & Total & 13.549 & 14.138 & 14.463 & 15.037 & 15.405 & 15.874 & 16.078 & 16.844 & 16.855 & $2,8^{* * *}$ \\
\hline \multirow{3}{*}{$\begin{array}{c}\text { Centro- } \\
\text { Oeste }\end{array}$} & Agrícola & 342 & 376 & 363 & 347 & 351 & 348 & 382 & 361 & 409 & $1,2^{* *}$ \\
\hline & Não agrícola & 4.404 & 4.594 & 4.588 & 4.899 & 4.944 & 5.119 & 5.404 & 5.667 & 5.753 & $3,5^{* * *}$ \\
\hline & Total & 4.745 & 4.969 & 4.950 & 5.246 & 5.295 & 5.467 & 5.785 & 6.028 & 6.162 & $3,4^{* * *}$ \\
\hline \multirow{3}{*}{ Sudeste } & Agrícola & 1.319 & 1.483 & 1.533 & 1.501 & 1.499 & 1.569 & 1.399 & 1.541 & 1.515 & 0,9 * \\
\hline & Não agrícola & 28.255 & 29.263 & 29.577 & 30.515 & 31.535 & 32.745 & 33.405 & 34.637 & 34.826 & $2,8^{* * *}$ \\
\hline & Total & 29.574 & 30.747 & 31.110 & 32.016 & 33.035 & 34.314 & 34.803 & 36.178 & 36.341 & $2,7^{* * *}$ \\
\hline \multirow{3}{*}{ Sul } & Agrícola & 729 & 857 & 857 & 824 & 837 & 832 & 709 & 683 & 617 & $-2,8^{* * *}$ \\
\hline & Não agrícola & 9.209 & 9.425 & 9.608 & 10.074 & 10.168 & 10.448 & 10.828 & 10.975 & 11.210 & $2,6^{* * *}$ \\
\hline & Total & 9.938 & 10.282 & 10.465 & 10.898 & 11.005 & 11.280 & 11.537 & 11.658 & 11.827 & $2,2 * * *$ \\
\hline
\end{tabular}

Fonte: Elaborado pelos autores com base nos microdados da Pesquisa Nacional de Amostra por Domicílios (PNAD), do Instituto Brasileiro de Geografia e Estatística (IBGE).

Notas: ${ }^{1}$ Taxa média anual de crescimento, estimada pelo coeficiente da regressão log-linear em função do tempo. Sendo que ***, ** * indicam, respectivamente, o nível de significância de 5\%, 10\% ou, 20\%, pelo teste $t$ de Student, e NS, não significativo.

Em relação à média da PEA urbana ocupada em atividades agrícolas entre 2001 e 2009, em termos absolutos, a Região Nordeste apresentou cerca de 1,9 milhão de pessoas. No entanto sua taxa de crescimento anual não foi significativa. A região Sudeste, por sua vez, com aproximadamente 1,5 milhão de pessoas, apresentou taxa de crescimento anual de $0,9 \%$ a.a. A região Sul, com uma média de 770 mil pessoas, foi a única que apresentou contração, 2,8\% a.a. Por fim, a região Centro-Oeste, com média de 365 mil pessoas, obteve crescimento médio de $1,2 \%$ a.a.

A região Nordeste atingiu uma média de participação relativa da PEA urbana ocupada em atividades agrícolas de $13 \%$, sendo a única, dentre todas as Grandes Regiões do estudo, em que a PEA urbana ocupada em atividades agrícolas foi superior a $10 \%$ durante o período analisado. No entanto a região obteve um decréscimo nas taxas de crescimento.

O Centro-Oeste atingiu uma média na participação relativa da PEA urbana ocupada em atividades agrícolas de $7 \%$, a mesma participação média da região Sul. Em relação às taxas de crescimento desse mesmo setor de atividade, houve decréscimo em ambas as regiões, sendo mais acentuada na segunda.

A região Sudeste atingiu a menor participação relativa da PEA urbana ocupada em atividades agrícolas, com média de $5 \%$ no período em tela. No entanto essa foi a região que deteve o menor decréscimo ao longo do período da participação relativa da PEA urbana ocupada em atividades agrícolas. 
Dessa forma, a participação relativa da PEA urbana ocupada em atividades agrícolas no meio urbano, de forma geral é irrisória, ou seja, sua participação é mínima em relação à PEA urbana ocupada total, não respondendo, de forma expressiva, às possíveis alterações existentes.

De modo geral, as Grandes Regiões vêm se destacando pela persistência da redução da PEA rural ocupada em atividades agrícolas, cuja redução tem sido mais do que compensada pela expansão da PEA rural ocupada em atividades não agrícolas. Tais tendências seguem o mesmo padrão daquelas observadas, no âmbito nacional, por Ferreira et al. (2006) e por Laurenti, Pellini e Telles (2015). Subentende-se, assim, que a redução da PEA rural ocupada em atividade agrícola é derivada, em parte, da contínua adoção de inovações na base técnica de produção e da reorganização do empreendimento agrícola (LAURENTI, 2014; MAIA; BUAINAIN, 2015).

As mudanças apresentadas para a região Centro-Oeste neste estudo já haviam sido constatadas em Balsadi (2008). Entre os resultados que o autor obteve para a região durante o período de 2001 a 2005, um dos mais marcantes foi o crescimento da PEA rural não agrícola a uma taxa de $6,1 \%$ a.a.

A dinâmica da PEA rural ocupada em atividades agrícolas e não agrícolas, ou seja, a perda da importância relativa da primeira em relação à segunda, verificada nesta pesquisa, foi anteriormente inferida por Ferreira et al. (2006). Para eles, tal tendência pode ser observada, sobretudo, nas regiões Centro-Oeste, Sul e, com maior intensidade, na Sudeste, sendo essa análise válida para o período de 1993 a 2004. Para fins de comparação, vale ressaltar que, entre 2001 e 2004, a região Centro-Oeste ficou estagnada, enquanto a perda de importância relativa da PEA rural ocupada em atividades agrícolas persistiu para as regiões Sudeste e Sul. No Sudeste, as referidas transformações no meio rural ocorreram com maior magnitude, mais especificamente no estado de São Paulo e do Rio de Janeiro, sendo que, durante o período de 1992 a 2001, a PEA rural ocupada em atividades não agrícolas já era superior àquela ocupada em atividades agrícolas (BALSADI; BORIN, 2006).

Em síntese, as transformações observadas a partir da relação da PEA total ocupada em atividades agrícolas e da PEA total ocupada, somadas às tendências da PEA urbana ocupada em atividades agrícolas versus a PEA urbana ocupada total e, por fim, da PEA rural ocupada total em relação aos subgrupos da PEA rural ocupada em atividades agrícolas e da PEA rural ocupada em atividades não agrícolas, ilustram uma grande heterogeneidade na dinâmica da população ocupada nas diferentes regiões do Brasil. Esses vetores dão indicativos de que o desigual processo de modernização da agricultura brasileira se apresentou com intensidades variadas entre as Grandes Regiões do país nos anos 2000. Os resultados desta pesquisa também evidenciam que, a fim de se contornar essa dinâmica, são necessárias ações públicas focadas no desenvolvimento rural e alinhadas à realidade de cada região.

\section{CONSIDERAÇÕES FINAIS}

Neste estudo, constataram-se, entre 2001 e 2009, quatro tendências em relação à PEA ocupada nas Grandes Regiões do Brasil. Quanto à participação relativa da PEA total ocupada por setor de atividade, observa-se a evolução da não agrícola e o declínio da agrícola em todas as Grandes Regiões. Em valores absolutos, de modo geral, houve redução da PEA total ocupada em atividades agrícolas em todas as Grandes Regiões do estudo, com exceção do Centro-Oeste. Acerca da participação da PEA rural ocupada por setor de atividade, verificou-se uma evolução da não agrícola e uma involução da agrícola para todas as Grandes Regiões. Para a PEA 
rural ocupada em atividades agrícolas, em valores absolutos, houve redução de modo geral para as regiões de análise, com ressalva à Grande Região CentroOeste, que não foi significativa. No caso da PEA rural ocupada em atividades não agrícolas, constatou-se um crescimento para todas as Grandes Regiões. Em relação à participação relativa da PEA urbana ocupada por setor de atividade, constatou-se um aumento da participação da não agrícola e uma diminuição da agrícola em todas as Grandes Regiões. Sendo que, em termos absolutos, a PEA urbana ocupada em atividades agrícolas do Sul é a única que decresceu durante o período analisado.

Nesse contexto, a redução da PEA ocupada em atividades agrícolas suscita questões, cujos resultados aqui apresentados não são suficientes para elucidar. Primeiro, se é a modernização da agricultura a principal responsável pela redução no número de postos de ocupação em atividades agrícolas ou, segundo, se as atividades agrícolas vêm deixando de ser atrativas à PEA rural, ou mesmo a contribuição de cada uma destas sobre tal declínio.

\section{REFERÊNCIAS}

ALVES, C. L. B.; PAULO, E. M. Mercado de trabalho rural cearense: evolução recente a partir dos dados da PNAD. Revista da ABET, São Paulo, v. 11, n. 2, p. 47-61, 2012.

BALSADI, O. V. Comportamento das ocupações na agropecuária brasileira no período 1999-2003. Informações Econômicas, São Paulo, v. 35, n. 9, p. 38-49, 2005.

BALSADI, O. V. Ocupações não agrícolas da população rural no Centro-Oeste brasileiro no período 2001-2005. Informações Econômicas, São Paulo, v. 38, n. 11, p. 39-47, 2008.

BALSADI, O. V.; BORIN, M. R. Ocupações agrícolas e não-agrícolas no rural paulista: análise das evoluções no período 1990-2002. São Paulo em Perspectiva, São Paulo, v. 20, n. 4, p. 155-174, 2006.
BALSADI, O. V.; GOMES, E. G. Evolução das condições de vida das famílias de empregados na agricultura brasileira no período 19922004. Revista de Economia Agrícola, São Paulo, v. 54, n. 2, p. 67-1014, 2007.

BAZOTTI, A.; NAZARENO, L. R.; CINTRA, A. P. U. Um ensaio sobre as famílias agrícolas paranaenses a partir das PNADs 1992, 1998, 2005 e 2007. Revista Paranaense de Desenvolvimento, Curitiba, n. 117, p. 123-145, 2009.

DEL GROSSI, M.; GRAZIANO DA SILVA, J. Mudanças recentes no mercado de trabalho rural. Parcerias Estratégicas, Brasília, v. 11, n. 22, p. 201-2016, 2006.

FERREIRA, B.; BALSADI, O. V.; FREITAS, R. E.; ALMEIDA, A. N. Ocupações agrícolas e não agrícolas: trajetória e rendimentos no meio rural brasileiro. In: DE NEGRI, J. A.; DE NEGRI, F.; COELHO, D. (Org.). Tecnologia, exportação e emprego. Brasília: IPEA, 2006. p. 445-488.

FREITAS, R. E.; MENDONÇA, M. A. A.; LOPES, G. O. Expansão de área agrícola nas mesorregiões brasileiras. Revista de Política Agrícola, Brasília, v. 20, n. 1, p. 100-116, 2011.

FROEHLICH, J. M. Gilberto Freyre, a história ambiental e a 'rurbanização' . História, Ciências, Saúde-Manguinhos, Rio de Janeiro, v. 7, n. 2, p. 283-303, 2000.

GRAZIANO DA SILVA, J. O novo rural brasileiro. Nova Economia, Belo Horizonte, v. 7, n. 1, 1997.

GRAZIANO DA SILVA, J. Velhos e novos mitos do rural brasileiro. Estudos Avançados, São Paulo, v. 15, n. 43, p. 37-50, 2001.

GRAZIANO DA SILVA, J.; DEL GROSSI, M. E. Rural nonfarm employment and incomes in Brazil: patterns and evolution. World Development, Oxford, v. 29, n. 3, p. 443-453, 2001.

HOFFMANN, R. Análise de regressão: uma introdução à econometria. 4. ed. São Paulo: Hucitec, 2006.

LAURENTI, A. C. Evolução da ocupação e do rendimento das pessoas no meio rural do Paraná no período 2001-2009. Revista Paranaense de Desenvolvimento, Curitiba, v. 34, n. 124, p. 175-199, 2013. 
LAURENTI, A. C. Ocupação e renda na nova ruralidade brasileira: tendências de variação na ocupação e no rendimento da população rural no período 2001-2009. Londrina, PR: IAPAR, 2014.

LAURENTI, A. C.; PELLINI, T.; TELLES, T.S. Evolução da ocupação e do rendimento das pessoas no espaço rural brasileiro no período de 2001 a 2009. Revista de Economia e Sociologia Rural, Brasília, v. 54, n. 2, p. 321-342, 2015.
MAIA, A. G.; BUAINAIN, A. M. O novo mapa da população rural brasileira. Confins, Paris, n. 25, p. 1-26, 2015.

SANTOS, M. A urbanização brasileira. 5. ed. São Paulo: Edusp, 2005.

SAUER, S.; LEITE, S. P. Expansão agrícola, preços e apropriação de terra por estrangeiros no Brasil. Revista de Economia e Sociologia Rural, Brasília, v. 50, n. 3, p. 503-524, 2012.

\section{Sobre os autores:}

Tiago Santos Telles : Instituto Agronômico do Paraná (IAPAR), Área de Socioeconomia, Londrina, PR. E-mail: telles@iapar.br

Gustavo Vaz da Costa: Instituto Agronômico do Paraná (IAPAR), Área de Socioeconomia, Londrina, PR. E-mail: gustavo.vaz.costa@gmail.com

Matheus Demambre Bacchi: Instituto Agronômico do Paraná (IAPAR), Área de Socioeconomia, Londrina, PR. E-mail: matheus.dbacchi@gmail.com

Antonio Carlos Laurenti: Instituto Agronômico do Paraná (IAPAR), Área de Socioeconomia, Londrina, PR. E-mail: laurenti@iapar.br 